\title{
Tropical cyclone triggering of sediment discharge in Taiwan
}

\author{
J. Galewsky, ${ }^{1}$ C. P. Stark, ${ }^{2}$ S. Dadson, ${ }^{3}$ C.-C. Wu, ${ }^{4}$ A. H. Sobel, ${ }^{5}$ and M.-J. Horng ${ }^{6}$ \\ Received 21 October 2005; revised 7 April 2006; accepted 5 June 2006; published 19 September 2006.
}

[1] The impact of tropical cyclones on precipitation variability and surface processes in Taiwan is studied using suspended sediment and river discharge data along with a meteorological model of tropical cyclone dynamics. The interactions between tropical cyclones and topography produce distinctive, localized patterns of heavy precipitation that can trigger high sediment discharge in Taiwan's rivers. We focus on Typhoon Toraji, which made landfall in Taiwan on 30 July 2001 and was the first major tropical cyclone to affect Taiwan after the 1999 Chichi earthquake. The passage of the tropical cyclone eye over the east coast of Taiwan produced intense rainfall $\left(>100 \mathrm{~mm} \mathrm{~h}^{-1}\right)$ for a short period (about 2 hours), triggering the highest sediment concentration ever recorded on the Hualien River. Orographic effects localized heavy rainfall (between 10 and $50 \mathrm{~mm} \mathrm{~h}^{-1}$ ) over the southwestern slopes of the Central Mountain Range, triggering high sediment discharge on the Kaoping River and flushing landslide debris produced during the Chichi earthquake into the Choshui River. We show that a range of atmospheric processes, with distinctive spatial variability and varying degrees of coupling to topography, interacted with tectonic processes of limited spatial extent to produce the overall sediment discharge from Taiwan during Typhoon Toraji. Landscape evolution models may need to be modified to account for the distinctive patterns of localized rainfall in tropical mountain belts. Furthermore, the links between tropical cyclones and topography suggest the potential for a range of previously unrecognized feedbacks between tectonics and climate in tropical mountain belts.

Citation: Galewsky, J., C. P. Stark, S. Dadson, C.-C. Wu, A. H. Sobel, and M.-J. Horng (2006), Tropical cyclone triggering of sediment discharge in Taiwan, J. Geophys. Res., 111, F03014, doi:10.1029/2005JF000428.

\section{Introduction}

[2] Precipitation plays a central role in the erosion of mountain belts by driving a wide range of hillslope, fluvial, and glacial processes. Atmospheric processes, coupled to topography via orographic effects, control the precipitation in mountain belts, thereby establishing the potential for feedbacks between climatic and tectonic processes during orogenesis. Many studies have shown that landscape evolution may be influenced by precipitation variability [Dunne, 1991; Tucker and Slingerland, 1997; Tucker and Bras, 2000; Sólyom and Tucker, 2004], and by its coupling to topography

\footnotetext{
${ }^{1}$ Department of Earth and Planetary Sciences, University of New Mexico, Albuquerque, New Mexico, USA.

${ }^{2}$ Lamont-Doherty Earth Observatory, Columbia University, Palisades, New York, USA.

${ }^{3}$ Centre for Ecology and Hydrology, Wallingford, UK.

${ }^{4}$ Department of Atmospheric Sciences, National Taiwan University, Taipei, Taiwan.

${ }^{5}$ Department of Applied Physics and Applied Mathematics, Columbia University, New York, New York, USA.

${ }^{6}$ Water Resources Agency, Ministry of Economic Affairs, Taipei, Taiwan.

Copyright 2006 by the American Geophysical Union. 0148-0227/06/2005JF000428\$09.00
}

[Roe et al., 2003], and that erosion driven by precipitation can exert a significant impact on the tectonics of mountain belts [Willett, 1999; Beaumont et al., 2001; Wobus et al., 2003; Hodges et al., 2004], but the precise links between meteorological processes, surface processes, and tectonics remain enigmatic [Molnar, 2003; Burbank et al., 2003].

[3] The erosion of some mountain belts on long timescales $\left(10^{6}-10^{7} \mathrm{yr}\right)$ has been understood in terms of relief and mean annual precipitation [Montgomery et al., 2001; Finlayson et al., 2002; Reiners et al., 2003]. In Taiwan, however, decadal-scale erosion is poorly described by this relationship and is better understood in terms of intermittent earthquake- and storm-triggered landslides and sediment transport [Dadson et al., 2004]. Apparently, the mean annual precipitation poorly describes the meteorological forcing of geomorphic processes in Taiwan; the frequency and intensity of extreme events are instead more important. The heaviest rainfall in Taiwan and many other tropical mountain belts, such as Hispaniola, Central America, Japan, and the Philippines, is associated with tropical cyclones [Brand and Blelloch, 1973, 1974; Bender et al., 1987; Hellin et al., 1999; Geerts et al., 2000; Grossman, 2001]. Tropical cyclone rainfall is spatially and temporally intermittent and is dependent on topography in more complex ways than the storms that affect mid-latitude mountain belts [Wu and Kuo, 


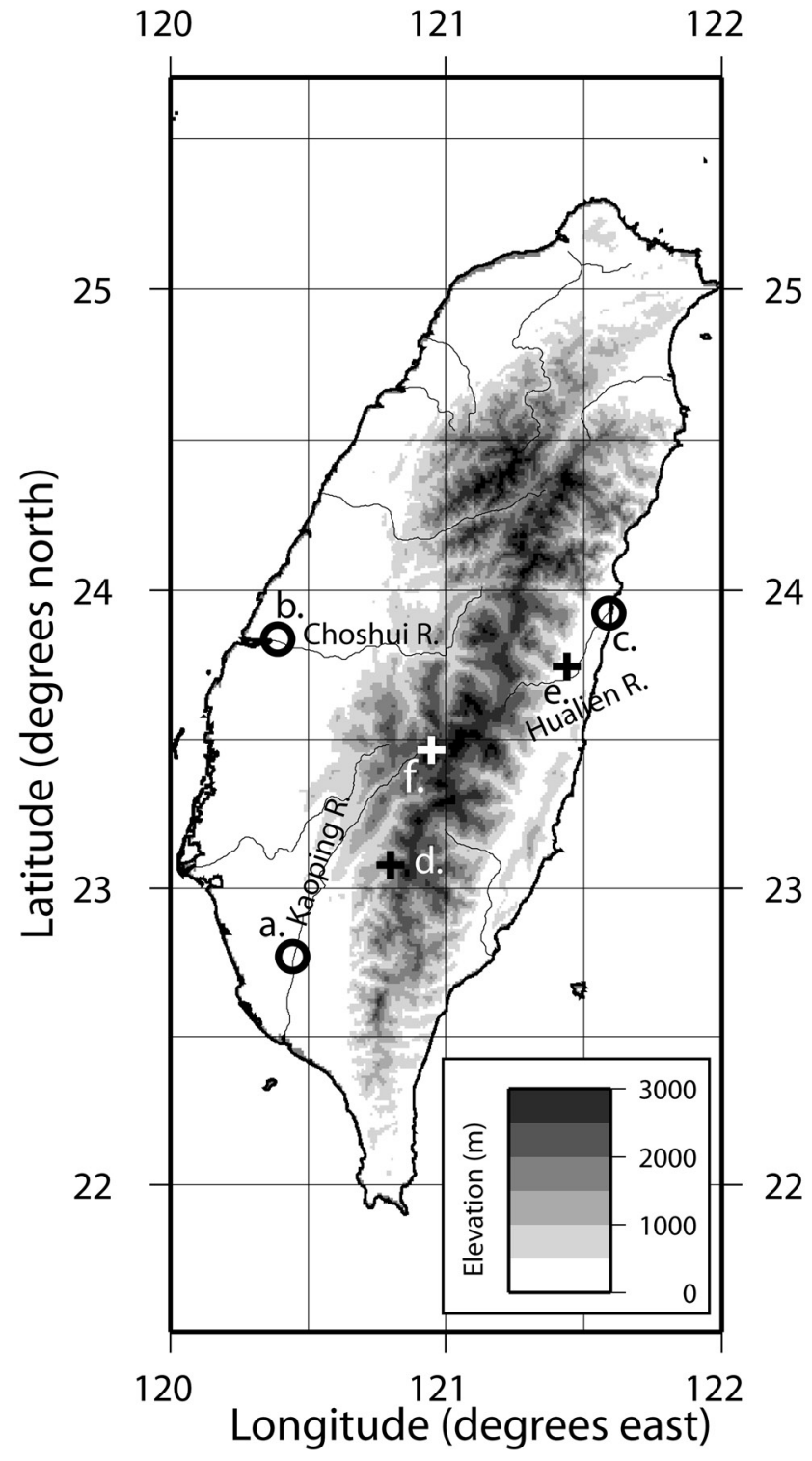

Figure 1. Location map of Taiwan. Circles indicate location of river gauging stations and crosses indicate location of rain gauges. Site a, Lilin Bridge, Kaoping River; site b, Ziuchian Bridge, Choshui River; site c, Hualien Bridge, Hualien River; site d, Shinan; site e, Fenglin; site f, Alishan.

1999; Wu, 2001; Wu et al., 2002; Lin et al., 2002; Chiao and Lin, 2003]. Thus a complete description of the geomorphology of tropical mountain belts and their interaction with their meteorological environment requires a better understanding of tropical cyclone rainfall variability and its impact on surface processes.

[4] The goal of this study is to use observations of precipitation and suspended sediment concentration along with a numerical simulation of tropical cyclone dynamics to investigate tropical cyclone precipitation variability in space and time, its coupling to topography, and its impact on landscape evolution in a tectonically active orogen. We focus on Taiwan during the period from 1996 through 2001, specifically on the geomorphic effects of Typhoon Herb (1996), the Chichi earthquake (1999), and, in particular, Typhoon Toraji (2001).
[5] Taiwan (Figure 1) is an active mountain belt formed by the oblique collision between the Luzon arc and the Asian continental margin [e.g., Teng, 1990]. The mountain belt consists of several ranges, including the Western Foothills fold and thrust belt, the Hsueshan Range, the Central Range, and the Coastal Range. The Central Range is the highest part of Taiwan and is a linear mountain belt with many peaks over $3000 \mathrm{~m}$ altitude. Rapid rates of geological processes and dense instrumentation make Taiwan an ideal locale for studying the interactions between landscape evolution and meteorology.

[6] The paper is structured as follows. Data used in this study are described in section 2. Background information about orographic precipitation and tropical cyclones is presented in section 3. Sections 4 and 5 describe the effects of Typhoon Herb (1996) and the Chichi earthquake (1999), respectively, which were two key events prior to Typhoon Toraji. Section 6 presents observations of rainfall and sediment transport during Typhoon Toraji. An atmospheric model of Typhoon Toraji is presented in section 7 and is used to diagnose the mechanisms of heavy precipitation during that event. Section 8 discusses the significance of

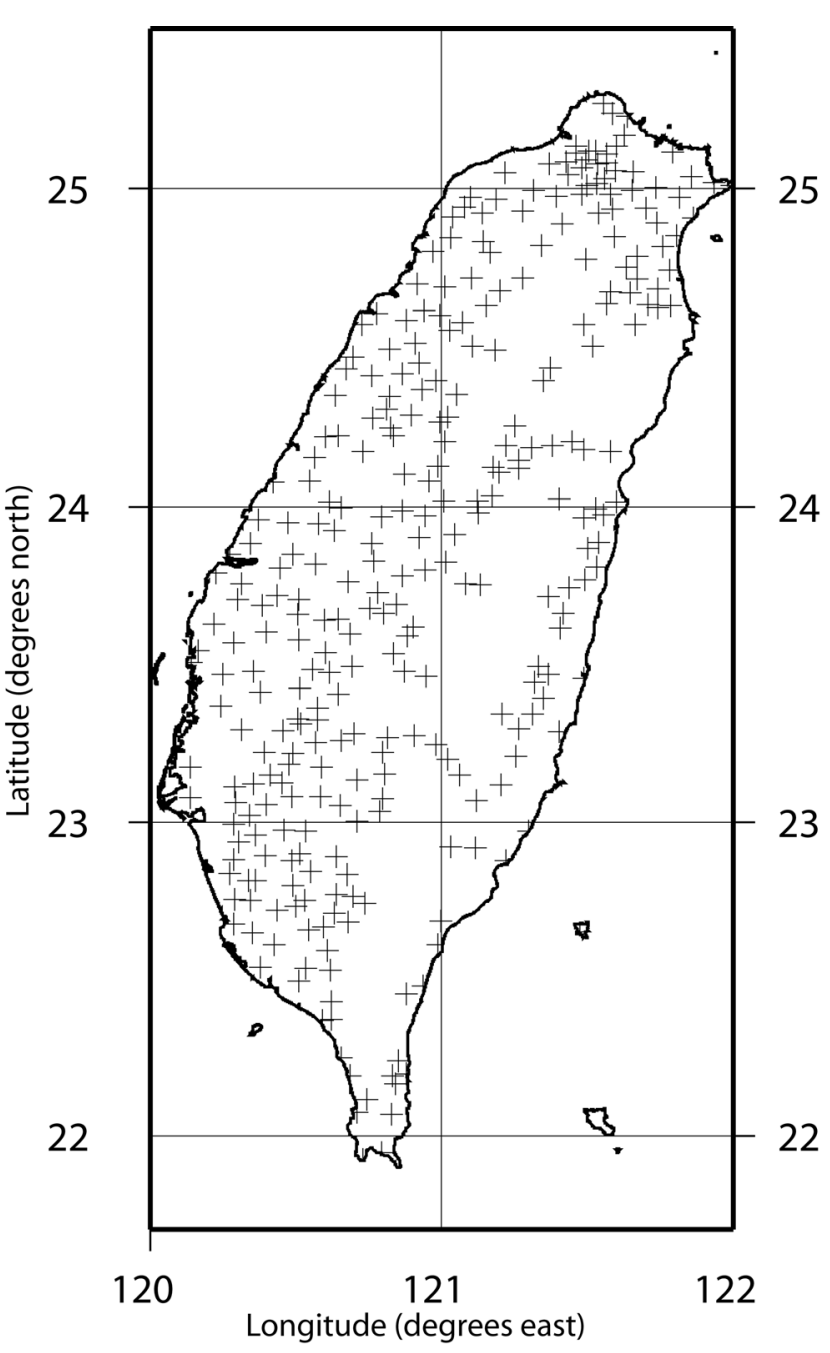

Figure 2. Locations of 326 rain gauges operated by the Taiwan Central Weather Bureau. 


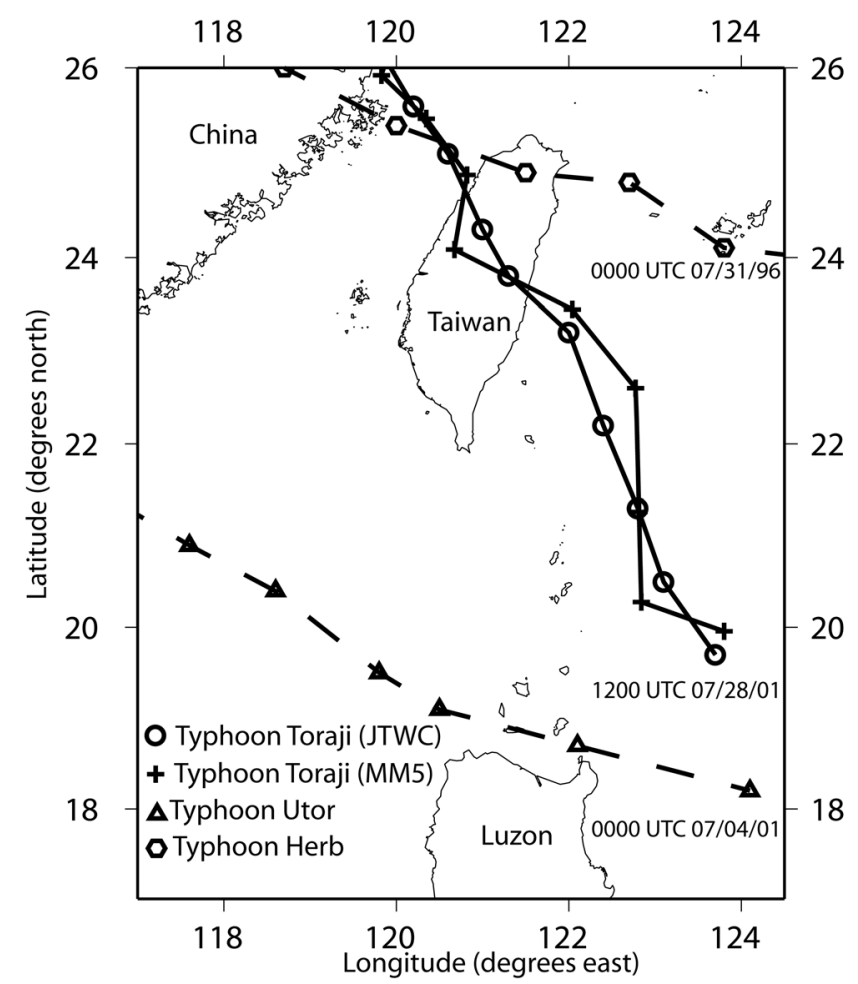

Figure 3. Joint Typhoon Warning Center (JTWC) best tracks for Typhoons Herb (31 July to 1 August 1996), Utor (4-5 July 2001), and Toraji (28-31 July 2001) showing position every 6 hours. Crosses indicate track of MM5 simulation of Typhoon Toraji.

these results for understanding landscape evolution in Taiwan and other tropical mountain belts.

\section{Data}

[7] Tropical cyclone track and intensity data were obtained from the Joint Typhoon Warning Center (JTWC). River discharge and fortnightly suspended sediment concentration data were obtained from stations operated by the Taiwan Water Resources Agency (Figure 1). Satellite data used in this study include wind data from the SeaWinds instrument on the QuikSCAT satellite and near-surface rain rate data from the precipitation radar aboard the Tropical Rainfall Measuring Mission (TRMM) satellite (2A25 algorithm). The rain gauge data (Figure 2) used in this study were recorded by the 326 automatic gauges operated by the Taiwan Central Weather Bureau. Basic quality assurance (QA) steps for the rain gauge data included the removal of stations with data drop-outs during the periods under consideration.

[8] The initial and boundary conditions for the numerical model presented here used the daily global analysis of atmospheric conditions from the European Centre for Medium-Range Weather Forecasting (ECMWF). This data set is a daily compilation of winds, temperature, and humidity on a 2.5 degree latitude-longitude grid at 22 vertical levels, and uses a numerical model to assimilate data from surface observations, weather balloons, and satellites into a dynamically consistent snapshot of atmospheric conditions. The model also employed sea surface temperatures provided by the National Centers for Environmental Prediction (NCEP).
Model topography was derived from the United States Geological Survey 30 arc second global topography data set (GTOPO30).

\section{Orographic Precipitation and Tropical Cyclones}

[9] The flow of air over topography can influence precipitation processes in several ways [Roe, 2005]. Perhaps the simplest case is when a stably stratified moist airstream impinges on a topographic barrier and is forced to rise. This forced ascent cools the air to the dewpoint temperature, causing saturation, condensation, and precipitation on windward slopes. Subsequent descent over leeward slopes warms the air above the dewpoint thereby suppressing rainfall, creating a rain shadow and, in some cases, creating the warm, dry downside winds known as föhn. Another mechanism involves the development of low-level orographic clouds over topography which can enhance large-scale precipitation through a "seeder-feeder" mechanism in which falling raindrops coalesce with the low-level orographic cloud droplets. A third mechanism of orographic enhancement can occur when potentially unstable air is orographically forced to rise above its level of free convection, triggering rapid buoyant ascent of the air and associated heavy precipitation, sometimes producing flash floods [e.g., Caracena et al., 1979]. Topography can also influence precipitation indirectly by blocking part of the flow, creating dynamical convergence between the blocked flow and the unblocked flow adjacent to it, enhancing rainfall where that convergence occurs [Rotunno and Ferretti, 2001; Galewsky and Sobel, 2005]. Regardless of the nature of the topographic interactions, cloud microphysical processes play a central role in determining the rate of raindrop formation and the fall time of precipitation [e.g., Houze, 1993].

[10] Over the open ocean, tropical cyclones (also called hurricanes or typhoons) can be idealized as antisymmetric atmospheric vortices in hydrostatic and gradient wind balance [Emanuel, 1991]. In cross-section, the circulation of a tropical cyclone consists of radial inflow and ascent within an eyewall 5 to $100 \mathrm{~km}$ from the storm center, and a radial outflow at the top of the storm. The eyewall of a tropical cyclone is an organized ring of cumulonimbus clouds surrounding the eye of the storm and is a site of intense rainfall and strong winds. Rainfall outside the eyewall may be organized into cyclonically curved spiral rainbands on the order of $10 \mathrm{~km}$ wide.

[11] Topography influences tropical cyclones in several ways. Even before a tropical cyclone makes landfall, topography can influence the storm track by deflecting the environmental flow that advects the storm [Yeh and Elsberry, 1993a; Bender et al., 1987; Brand and Blelloch, 1974]. Once the storm makes landfall, topography can severely distort the circulation of the storm, and in some cases the vortex may subsequently reorganize downstream of the topography yielding a discontinuous track across a mountainous island [Yeh and Elsberry, 1993b].

[12] As tropical cyclones pass over mountainous islands like Taiwan, heavy rainfall is produced in the eyewall and spiral rainbands (as would be expected in any tropical cyclone) and may be also produced via orographic enhancement as the tropical cyclone circulation (counterclockwise in 

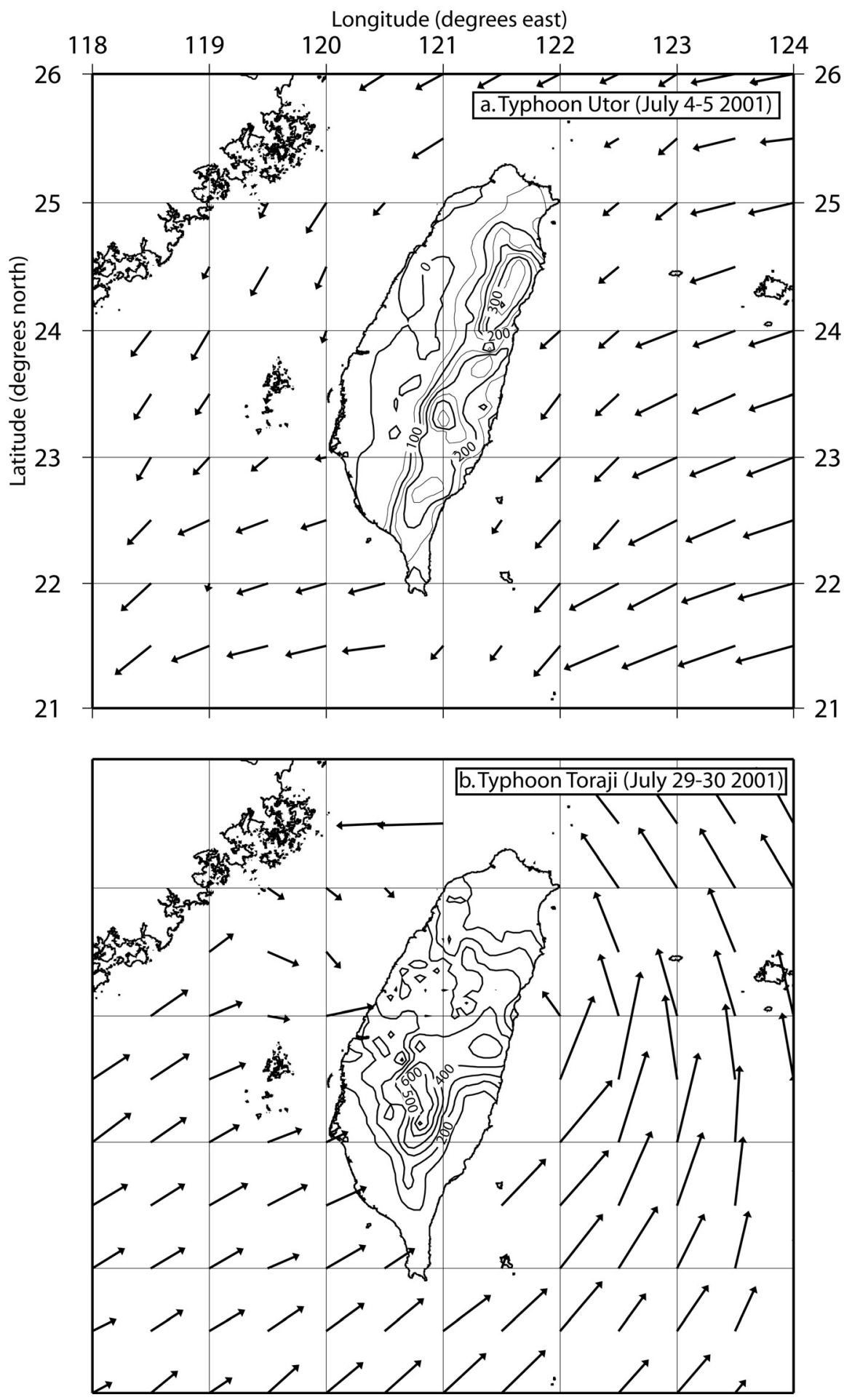

Figure 4. Accumulated rainfall (contours, $\mathrm{mm}$ ) and mean marine winds (vectors, averaged from Quikscat satellite data for the dates indicated) for the tropical cyclones that affected Taiwan during July 2001. (a) Typhoon Utor. (b) Typhoon Toraji.

the Northern Hemisphere) forces air upslope [Wu et al., 2002; Chiao and Lin, 2003]. We introduce some orographic influences on tropical cyclone rainfall by considering two tropical cyclones that affected Taiwan in July 2001 (Figures 3 and 4).

[13] Typhoon Utor (4-5 July 2001) passed to the south of Taiwan and did not make a direct landfall on the island. The cyclonic winds of the storm set up easterly onshore winds that brought heavy rainfall $(>300 \mathrm{~mm})$ to the eastern slopes of the Taiwan mountains, while leaving the western slopes in the lee relatively dry (Figure 4a).

[14] Typhoon Toraji (29-30 July 2001, Figure 4b) made a direct landfall on the east coast of Taiwan, and the cyclonic winds associated with the storm set up a complex pattern of orographic enhancement in southwestern and northeastern 


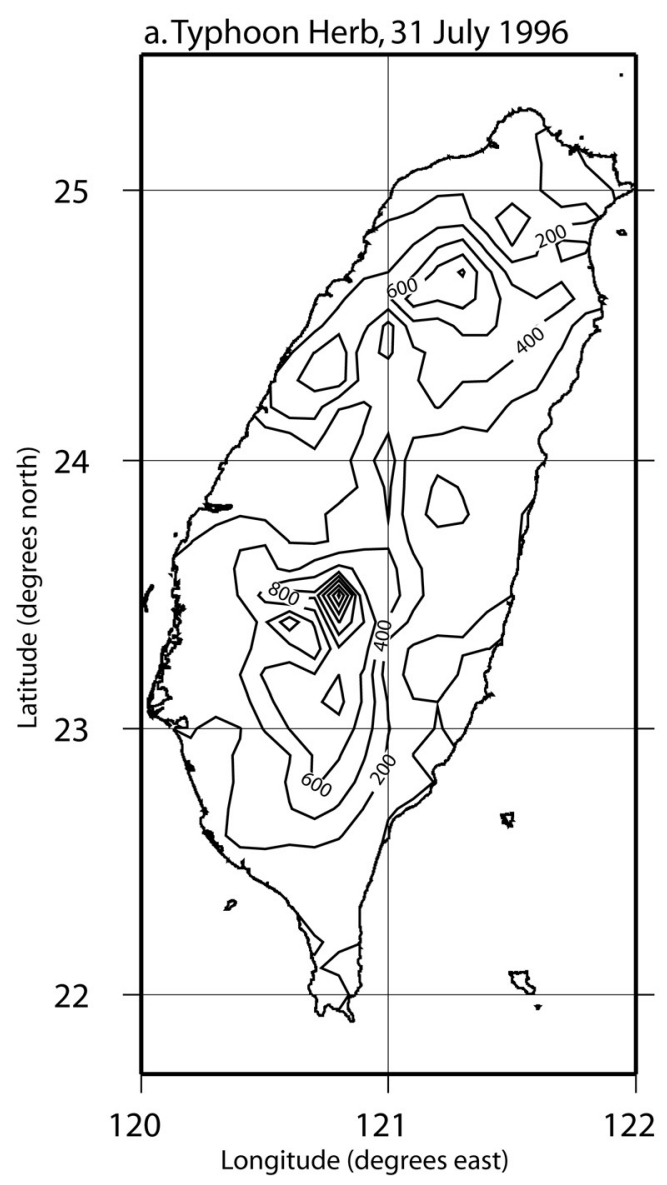

b.Typhoon Toraji, 29-30 July 2001

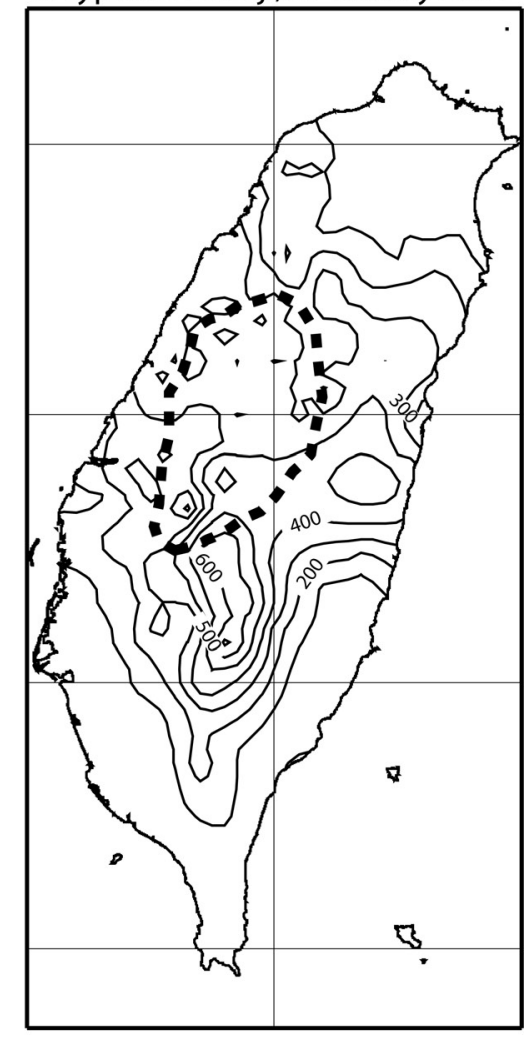

Figure 5. Accumulated rainfall during passage of (a) Typhoon Herb, 31 July 1996. (b) Typhoon Toraji, 29-30 July 2001. Contour interval is (a) $200 \mathrm{~mm}$ and (b) $100 \mathrm{~mm}$. Thick dashed line in Figure 5b indicates zone of maximum ground motion during the Chi-Chi earthquake of 21 September 1999, defined by contour of 0.2-g peak vertical ground acceleration [Lee et al., 2001].

Taiwan, while the southeastern slopes of the Taiwan mountains were in the lee during the storm and received much less rainfall. Heavy rainfall was also produced in eastern Taiwan by the eyewall of the storm as it traversed Taiwan. Note that heavy rainfall was produced on the southwestern slopes of the mountain belt, even though the storm approached from the southeast. This counterintuitive result is due to the particular way that tropical cyclones interact with topography, and will be discussed in much more detail below.

\section{Typhoon Herb}

[15] Typhoon Herb made landfall at Ilan in northeastern Taiwan on 31 July 1996 as a category 5 storm on the SaffirSimpson scale (Figure 3 ) and was one of the most destructive tropical cyclones on record in Taiwan. It brought sustained surface winds of $65 \mathrm{~m} \mathrm{~s}^{-1}$ and torrential rainfall throughout much of Taiwan (Figure 5a). Rainfall was orographically enhanced on the southwestern slopes of the Central Mountain Range [Wu et al., 2002] where moisture-laden winds were forced upslope by the southwesterly winds. Alishan (Figure 1) received a record-breaking $1736 \mathrm{~mm}$ of rainfall on 31 July 1996, with some regions of the Central Range receiving more than 20 hours of rainfall in excess of $20 \mathrm{~mm} \mathrm{hr}^{-1}$.
[16] The intense rainfall triggered slope failure across the area and produced high runoff and sediment discharge in several rivers. On the Kaoping River, Typhoon Herb generated the highest river discharge $\left(\mathrm{Q}=19,700 \mathrm{~m}^{3} \mathrm{~s}^{-1}\right)$ and sediment concentration $\left(C=30 \mathrm{~g} \mathrm{~L}^{-1}\right.$ measured at $Q=$ $13,800 \mathrm{~m}^{3} \mathrm{~s}^{-1}$ ) ever recorded on that river (Figure 6a). On the Choshui River, Typhoon Herb produced the highest river discharge ever recorded there $\left(18,500 \mathrm{~m}^{3} \mathrm{~s}^{-1}\right)$, and the highest sediment concentration recorded prior to Typhoon Toraji $\left(67 \mathrm{~g} \mathrm{~L}^{-1}\right.$ measured at $\left.Q=9420 \mathrm{~m}^{3} \mathrm{~s}^{-1}\right)$ (Figure $6 \mathrm{~b}$ ).

[17] The orographic effects on Typhoon Herb were studied by Wu et al. [2002], who used numerical simulations of the storm dynamics to diagnose the interactions between topography and the typhoon circulation. They showed that the cyclonic winds of the typhoon forced air upslope near Alishan, producing a maximum vertical wind speed and maximum condensational heating just above the surface, indicating that the heavy rainfall in southwest Taiwan was controlled by orographic effects. In the eyewall of Typhoon Herb, these maxima were instead located in the middle to upper troposphere, a profile typical of oceanic typhoons not influenced by orographic effects [Wu and Kurihara, 1996]. The record sediment discharge on the Kaoping and Choshui 

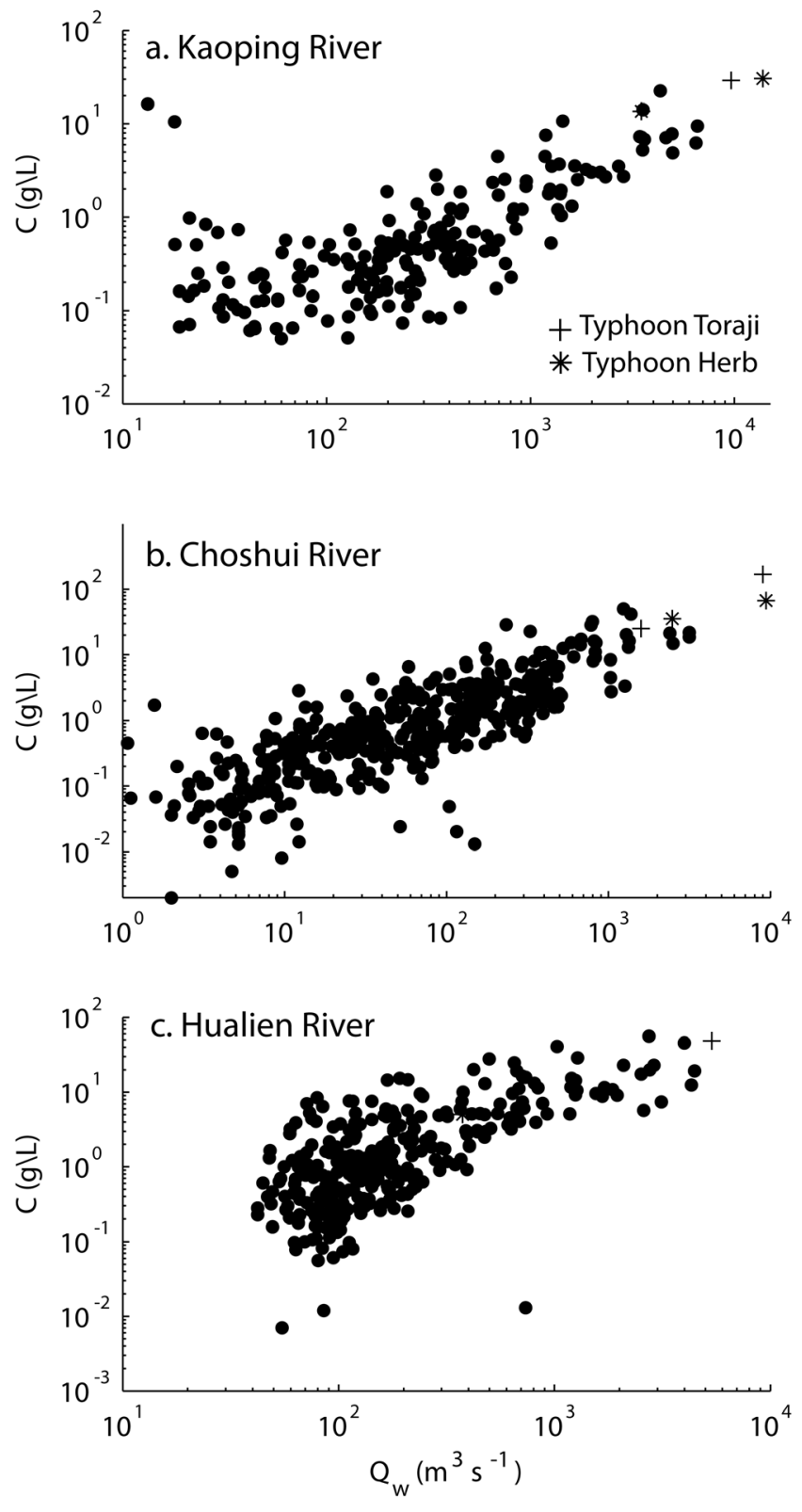

Figure 6. Suspended sediment concentration (C) versus water discharge $\left(Q_{w}\right)$ for the period 1970-2003 for (a) Kaoping River, (b) Choshui River, and (c) Hualien River. Data collected fortnightly by the Taiwan Water Resources Agency. Asterisks and crosses indicate peak sediment concentrations measured during Typhoon Herb and Typhoon Toraji, respectively.

Rivers were thus a consequence of orographically enhanced tropical cyclone rainfall.

\section{Chichi Earthquake}

[18] Three years after Typhoon Herb, the $M_{w}$ 7.6 Chi-Chi earthquake struck Taiwan on 21 September 1999, the largest earthquake in Taiwan for at least 50 years. The earthquake focal depth was relatively shallow $(8 \mathrm{~km})$ and produced ground accelerations of up to $1 \mathrm{~g}$ that triggered more than 20,000 soil and bedrock landslides throughout west-central
Taiwan [Lin et al., 2000] (Figure 5b). Dadson et al. [2004] showed that the unit sediment concentration (i.e., suspended sediment concentration for a unit water discharge) at the mouth of the Choshui River basin increased by a factor of 3.8 following the earthquake owing to the delivery of earthquake-triggered landslide debris to the river; this factor was even higher in mountainous catchments closer to the epicenter of the earthquake.

[19] Dadson et al. [2004] also showed that the total mass removed from the Choshui basin during the period between the Chichi Earthquake and the end of 2001 was $326 \mathrm{Mt}$, $175 \mathrm{Mt}$ of which was removed by Typhoon Toraji over a period of only 2 days. Their results thus show a complex relationship between coseismic sediment production and subsequent transport during tropical cyclones.

\section{Typhoon Toraji}

[20] Data from the Joint Typhoon Warning Center (JTWC) show that Typhoon Toraji formed in the Philippine Sea in late July 2001 and moved to the northwest, striking the east coast of Taiwan at 1600 UTC on 30 July 2001 (Figure 3) as a category 3 tropical cyclone on the SaffirSimpson scale with maximum wind speeds of around $50 \mathrm{~m} \mathrm{~s}^{-1}$. The typhoon caused more than 100 fatalities, making Toraji the deadliest typhoon to hit Taiwan since 1961.

[21] Along the Kaoping River, Typhoon Toraji produced peak river discharges of $10,000 \mathrm{~m}^{3} \mathrm{~s}^{-1}$, second only to those produced during Typhoon Herb, and sediment concentrations within $5 \%$ of those produced during Typhoon Herb (29 $\mathrm{g} \mathrm{L}^{-1}$ measured at $Q=9,640 \mathrm{~m}^{3} \mathrm{~s}^{-1}$ ) (Figure 6a). On the Choshui River (Figure 6b), Typhoon Toraji produced sediment concentrations more than twice those measured during Typhoon Herb $\left(169 \mathrm{~m}^{3} \mathrm{~s}^{-1}\right.$ measured at $\left.Q=8,900 \mathrm{~m}^{3} \mathrm{~s}^{-1}\right)$ and a peak water discharge of $28,000 \mathrm{~m}^{3} \mathrm{~s}^{-1}$. Typhoon Toraji also produced the highest discharges ever recorded on the Hualien River $\left(11,600 \mathrm{~m}^{3} \mathrm{~s}^{-1}\right)$ and the second highest sediment concentration $\left(49 \mathrm{~g} \mathrm{~L}^{-1}\right.$ recorded at $Q=5,350 \mathrm{~m}^{3} \mathrm{~s}^{-1}$ ) (Figure 6c).

[22] The Chichi earthquake had a direct effect on the amount of sediment available for the Choshui River to transport during and immediately after Typhoon Toraji. Dadson et al. [2004] showed that the coseismic debris that had been produced during the Chichi earthquake was flushed from hillsides into river channels during Typhoon Toraji, resulting in abnormally high sediment concentration on the Choshui River (even given the high water discharge). In contrast, the Kaoping and Hualien Rivers, which are largely outside of the area affected by the strongest earthquake ground motion (Figure 5b), also received heavy rainfall during Typhoon Toraji and experienced concomitant high sediment discharge, but the sediment discharge on these rivers was not as high, relative to the water discharge, as was observed on the Choshui River (see Dadson et al. [2004] for more details on this point). Thus the sediment discharge associated with Typhoon Toraji was linked to both tropical cyclone and earthquake triggered sediment production and transport.

[23] As in Typhoon Herb, precipitation was especially heavy along the western flanks of the Central Range (Figure 5b). The maximum total precipitation for Typhoon Toraji was $750 \mathrm{~mm}$, recorded at Alishan. Ten other rain 


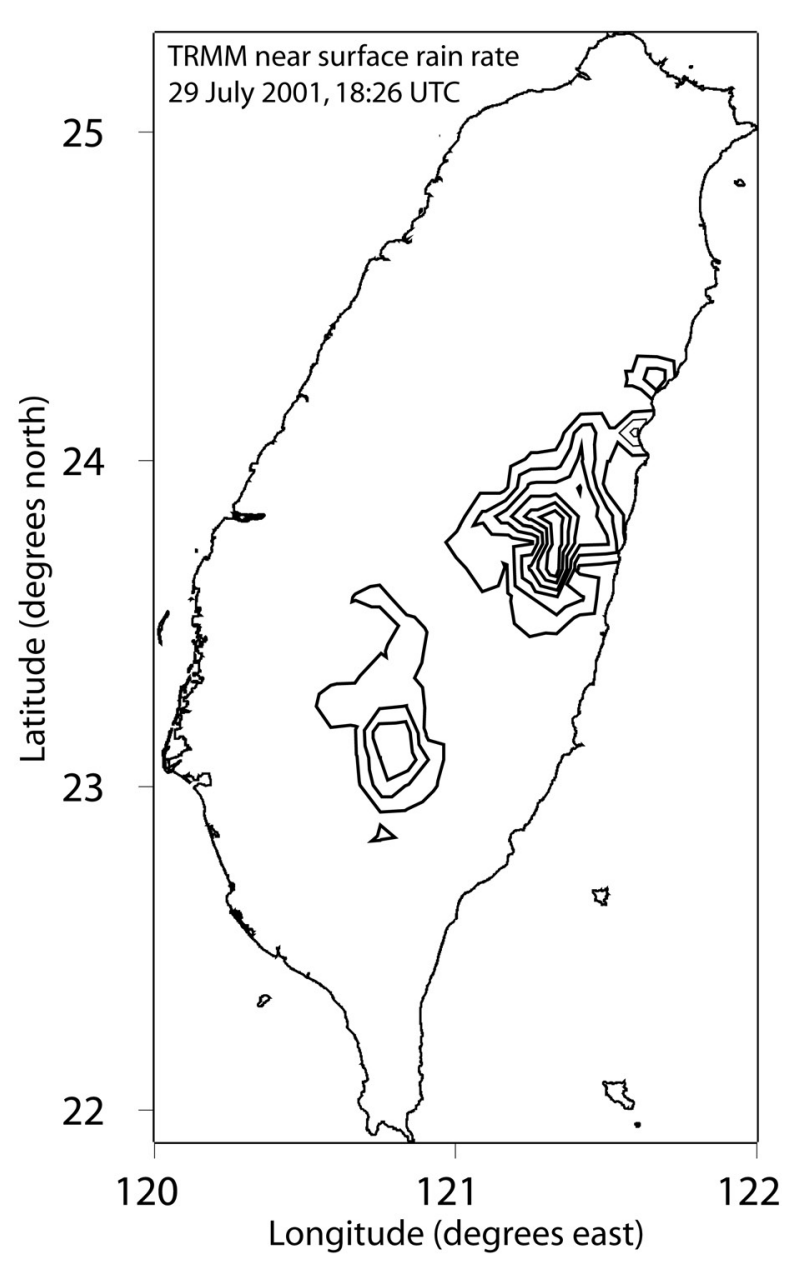

Figure 7. Instantaneous near-surface rain rates at 1826 UTC on 29 July 2001 derived from TRMM precipitation radar data. Contour interval is $30 \mathrm{~mm} \mathrm{~h}^{-1}$.

gauges in the Central Range near Alishan recorded more than $500 \mathrm{~mm}$ of rain. The storm made landfall on Taiwan's East coast near Fenglin (Hualien County), which received 570 $\mathrm{mm}$ of rain, the highest amount recorded on the East coast.

[24] Near-surface rain rate data obtained by the precipitation radar aboard the TRMM satellite just after Typhoon Toraji made landfall show two distinct zones of intense rainfall (Figure 7). Rain rates in excess of $180 \mathrm{~mm} \mathrm{~h}^{-1}$ were associated with the eyewall in eastern Taiwan while a secondary zone of rainfall with rain rates just over $90 \mathrm{~mm} \mathrm{~h}^{-1}$ was observed in the southwestern Central Range. These observations are consistent with the orographic enhancement mechanisms introduced above.

[25] A comparison of rain rates recorded by surface-based rain gauges further shows significant differences between the precipitation processes on the East Coast and in the southwestern Central Range. Forty percent of the total rain at Fenglin fell during only 2 hours of intense rain, at a rate in excess of $100 \mathrm{~mm} \mathrm{~h}^{-1}$ (Figure 8). However, Fenglin received only 1 hour of rainfall at a rate between 10 and $50 \mathrm{~mm} \mathrm{~h}^{-1}$. In the southwestern Central Range, Shinan (see Figure 1), which also received a total rainfall of $570 \mathrm{~mm}$, never recorded rainfall in excess of $100 \mathrm{~mm} \mathrm{~h}^{-1}$ but did record 11 hours of rainfall between 10 and $50 \mathrm{~mm} \mathrm{~h}^{-1}$. Rain gauges within the zone affected by the Chichi Earthquake (not shown) recorded a rain rate distribution similar to those at Shinan.

[26] These results show that the east coast of Taiwan received much more intense rainfall than the southwestern Central Range, even though the storm totals were similar at many locations. These differences suggest that different precipitation mechanisms may have driven the sediment discharge in the southwestern Central Range and around the landfall zone. This possibility, and its implications, are explored in the next sections.

\section{Numerical Model}

[27] Ideally, one would use direct observations of the atmosphere to understand the interactions between tropical cyclones and topography in Taiwan. Unfortunately, even on an island as well instrumented as Taiwan, the observational network is far too sparse to resolve the spatial and temporal variability of the atmosphere during a tropical cyclone. Instead, we performed a numerical simulation of Typhoon Toraji with a standard mesoscale meteorological model and used the model-derived fields to diagnose the interactions between the tropical cyclone circulation and the topography of Taiwan. The goal is not necessarily to compare specific features in the simulation to specific features in the observed storm, but rather to identify and describe basic processes simulated by the model and use them as an aid for understanding how Typhoon Toraji influenced surface processes in Taiwan.

\subsection{Model Configuration}

[28] Meteorological models consist of two main components: a dynamical core for numerically solving the equations of atmospheric motion, and a physics package that simulates

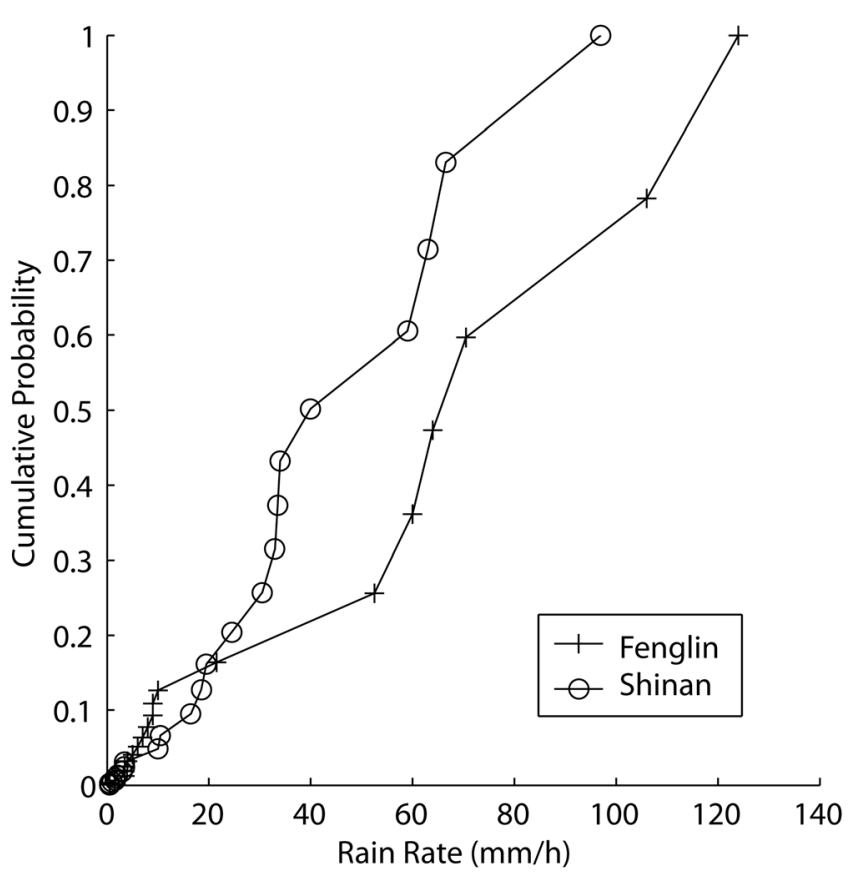

Figure 8. Cumulative distribution of rain rates during Typhoon Toraji at Fenglin (near the landfall site) and Shinan (on the western slopes of the Central Range). 


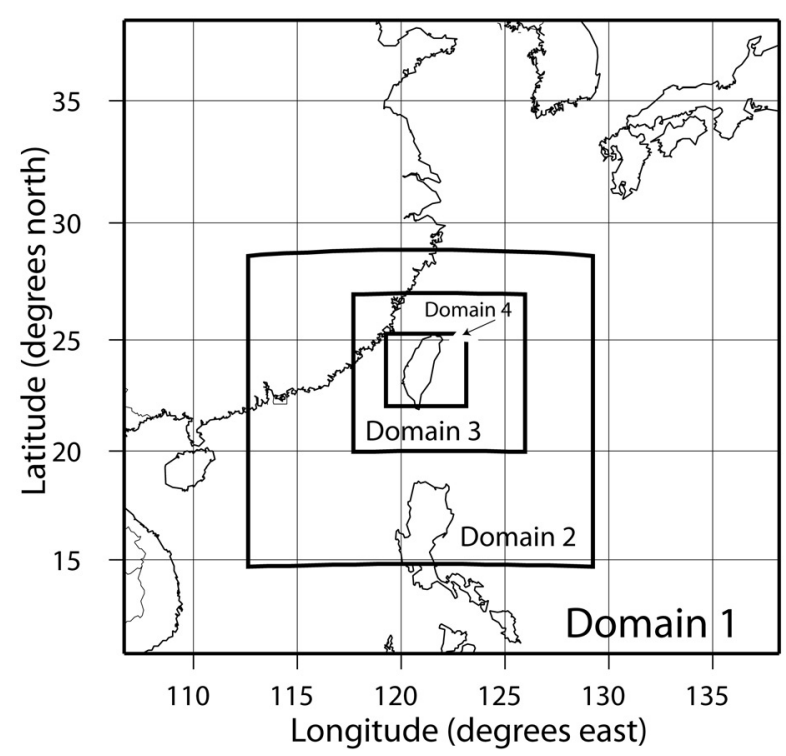

Figure 9. Nesting scheme for MM5 meteorological model.

subgrid-scale and external processes such as cloud microphysics, atmospheric radiation, moist convection, and land surface heat fluxes. Many meteorological models support nested domains for higher-resolution simulations over regions of particular interest. There are a variety of vertical coordinates used in meteorological models; a terrain-following vertical coordinate is often used for simulations involving mountainous topography.

[29] Meteorological models are typically initialized with a representation of the atmospheric state derived from surface, upper air, and satellite observations that are combined to form a dynamically consistent data set (usually called a "global analysis"). During the model run, the boundary conditions are also set by data from the global analysis. There are several global analysis data sets available from the U.S. National Centers for Environmental Prediction (NCEP) and from the European Centre for Medium-Range Weather Forecasting (ECMWF) that can be used with meteorological models. Simulation of tropical cyclones poses a special problem for meteorological models. Global analysis are typically too coarse to resolve the tight circulation of most tropical cyclones, so the initial state of the tropical cyclone vortex must be explicitly prescribed during initialization through a process called "bogussing."

[30] Meteorological models output many different computed fields, including horizontal and vertical winds, temperature, and moisture fields such as water vapor, cloud water, and rain water. One of the benefits of using a full meteorological model over simpler parameterizations [e.g., Roe et al., 2002; Masek et al., 1994] is that meteorological models simulate a much wider range of precipitation processes, including condensation, evaporation, and the advection of precipitation. All of these processes can, in principle, be diagnosed from the model output fields.

[31] The numerical simulations presented here were carried out with the Penn State-NCAR Fifth Generation Mesoscale Model (MM5 version 3). The dynamical core of MM5 solves the compressible, nonhydrostatic equations of motion using a finite difference formulation [Dudhia, 1993]. The physics package includes many different options for each physics component. Our selection of physics options was guided by the sensitivity experiments described below. The simulation presented here uses four successively nested computational domains centered over Taiwan with a horizontal grid spacing of $45 \mathrm{~km}, 15 \mathrm{~km}, 5 \mathrm{~km}$, and $1.666 \mathrm{~km}$, respectively (Figure 9), and the model uses 31 unevenly spaced terrain-following vertical levels. We use standard parameterizations for subgrid-scale processes, including the Bets-Miller scheme to parameterize subgrid-scale convection [Betts and Miller, 1993] in the outer two domains, the cloud microphysics scheme of Dudhia [1989], the Hong-Pan planetary boundary layer parameterization [Hong and Pan, 1996], and a simple five layer soil model to provide enthalpy fluxes to the atmospheric model [Dudhia, 1996].

[32] Atmospheric initial conditions from the ECMWF global analysis were interpolated to the MM5 Lambert conformal grid to provide the initial conditions at 0000 UTC 28 July 2001 and the 12-hour boundary conditions to the $45-\mathrm{km}$ outer domain. The inner domains received lateral boundary conditions from the outer domains during the model integration. We used the bogussing technique of Davis and Low-Nam [2001] to produce the initial tropical cyclone vortex. The simulation began at 1200 UTC 28 July 2001 and ended at 1200 UTC 31 July 2001.

\subsection{Model Sensitivity}

[33] The criteria for evaluating the success or failure of a meteorological simulation depend on the requirements of the application. For this study, we are primarily interested in understanding the links between tropical cyclone circulation and precipitation during Typhoon Toraji. An accurate simulation of the tropical cyclone track is therefore the most important feature we seek in this simulation, because that determines where the cyclonic flow will be forced upslope, and, hence, where the heavy precipitation will be focused. The simulated precipitation field is a useful indicator of the overall success of the simulation, but is subjected to compounded errors in track, winds, temperature, and humidity.

[34] We performed approximately 20-30 simulations of Typhoon Toraji using a wide range of model configurations and global analysis data sets. The biggest challenge was an accurate simulation of the tropical cyclone track, because most model configurations produced simulated tracks that passed well to the north of Taiwan. Once the track simulation was established, we found that other aspects of the simulation were relatively insensitive to model configuration and physics options. Thus we are confident that the simulation presented here is the best available given the modeling system used, and that the interpretations are robust.

[35] By far, the greatest model sensitivity was to the initial vortex bogussing parameters (see $W u$ [2001] for further examples). In the formulation of Davis and Low-Nam [2001], these parameters are (1) maximum wind speed, (2) radius of maximum wind, and (3) a wind speed scaling factor controlling the decay of winds away from the vortex center. For the simulations presented here, we used values of $55 \mathrm{~m} \mathrm{~s}^{-1}, 100 \mathrm{~km}$, and 0.87 , respectively. Small changes in any of these parameters produced simulated tropical cyclones with tracks very different from that observed; in fact, much of the bogussing parameter 


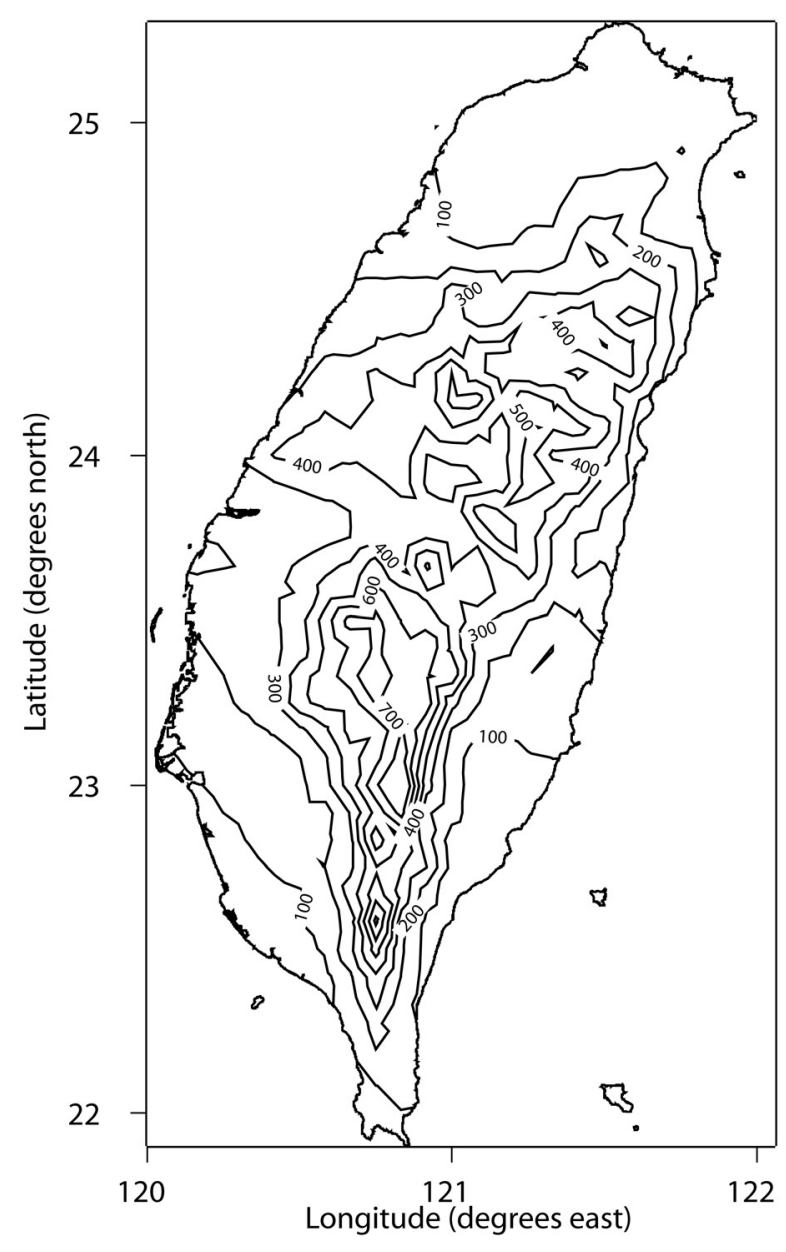

Figure 10. MM5 simulated accumulated rainfall during Typhoon Toraji (mm), 28-31 July 2001. Contour interval is $100 \mathrm{~m}$.

space yielded simulated tropical cyclones that passed to the north of Taiwan entirely. We took a pragmatic approach to the bogussing problem and simply sought those parameters that were physically reasonable and accurately simulated the observed track.

[36] We also evaluated several different domain configurations and grid spacings. For our purposes, an accurate representation of topography is of paramount importance because we want to understand how tropical cyclone circulations are influenced by mountainous topography. High horizontal resolution is therefore necessary to resolve the effects of topography. We evaluated several grid spacings, ranging from $10 \mathrm{~km}$ down to $1.6 \mathrm{~km}$. Our results were similar to those of Wu et al. [2002] and Chiao and Lin [2003], who showed that grid spacing greater than around $6 \mathrm{~km}$ was insufficient to simulate the observed rainfall associated with tropical cyclones over Taiwan. Furthermore, we found that a $1.6-\mathrm{km}$ grid spacing was required to simulate the spatial distribution of rainfall.

[37] One of the advantages of using high horizontal resolution $(<10 \mathrm{~km})$ is that moist convection can be explicitly resolved by the model. No parameterization of convective processes is required in the inner model domains, thereby removing one of the most sensitive components of a tropical cyclone simulation [Wang, 2002]. We assessed the sensitivity of the tropical cyclone simulation to different formulations of the cloud microphysics scheme, which is the part of the model that simulates the condensation of water vapor into cloud water and the production of precipitation from cloud water. We compared two different microphysics schemes, those of Dudhia [1989] and Tao and Simpson [1993]. The simulated track of the tropical cyclone was essentially unaffected by the choice of microphysics scheme, and differences in the simulated precipitation were no more than a few percent, consistent with the results of Wang [2002]. For the results presented below, we therefore used the microphysics scheme of Dudhia [1989] because of its greater numerical efficiency.

\subsection{Model Results and Analysis}

[38] Figure 3 shows the comparison of the simulated track with the best track analysis from the JTWC. Although the simulated track oscillates slightly around the observed track, the simulated tropical cyclone makes landfall over Taiwan at the observed location and time and is thus adequate for our application. After landfall, however, the simulated storm traverses Taiwan more rapidly than was observed. The simulated rainfall accumulation for Typhoon Toraji in Taiwan is shown in Figure 10. The magnitude and spatial distribution of rainfall is generally well simulated, with some exceptions. The model underestimates the rainfall in the coastal landfall zone by more than a factor of 2 at some sites, which may be at least partially owing to the rapid transit of the simulated storm across Taiwan. In addition, the model overestimates rainfall in the southern parts of the Central Range. Farther to the north, in the Alishan area, the precipitation simulation is quite good, and the simulated time evolution of rainfall (not shown) in this region matches quite well with rain gauge data.

[39] Figure 11 shows the simulated near-surface winds, short-term (3-hour) rainfall, and topography at 1600 UTC on 31 July 2001. The modeled winds clearly show the cyclonic circulation of the tropical cyclone winds and illustrate how they interacted with topography to produce the observed spatial distribution of rainfall. The storm approached Taiwan from the southeast, bringing heavy rain and high winds to the east coast of Taiwan where the eye of the storm made landfall. Easterly onshore winds also brought heavy rain to the northeastern part of the Central Range. In addition, the cyclonic winds circulated around the western side of Taiwan, coming onshore in the southwest to produce heavy rainfall along the southwestern flanks of the Central Range. Thus, even though the storm traveled from the southeast, the three-dimensional nature of the storm circulation produced heavy rainfall in the southwestern part of the Central Range.

[40] A useful diagnostic for assessing precipitation generation mechanisms is the latent heating associated with the condensation of water vapor into cloud water. Condensation is the first and most important step in the precipitation process and is especially sensitive to vertical winds because they transport water vapor to higher and cooler regions where condensation occurs. Downstream processes, such as rain drop advection and subcloud evaporation of precipitation may influence the ultimate surface precipitation distribution, but the location of condensation is a parameter of prime interest. 
$120 \mathrm{E}$ 1600 UTC 29 July 2001

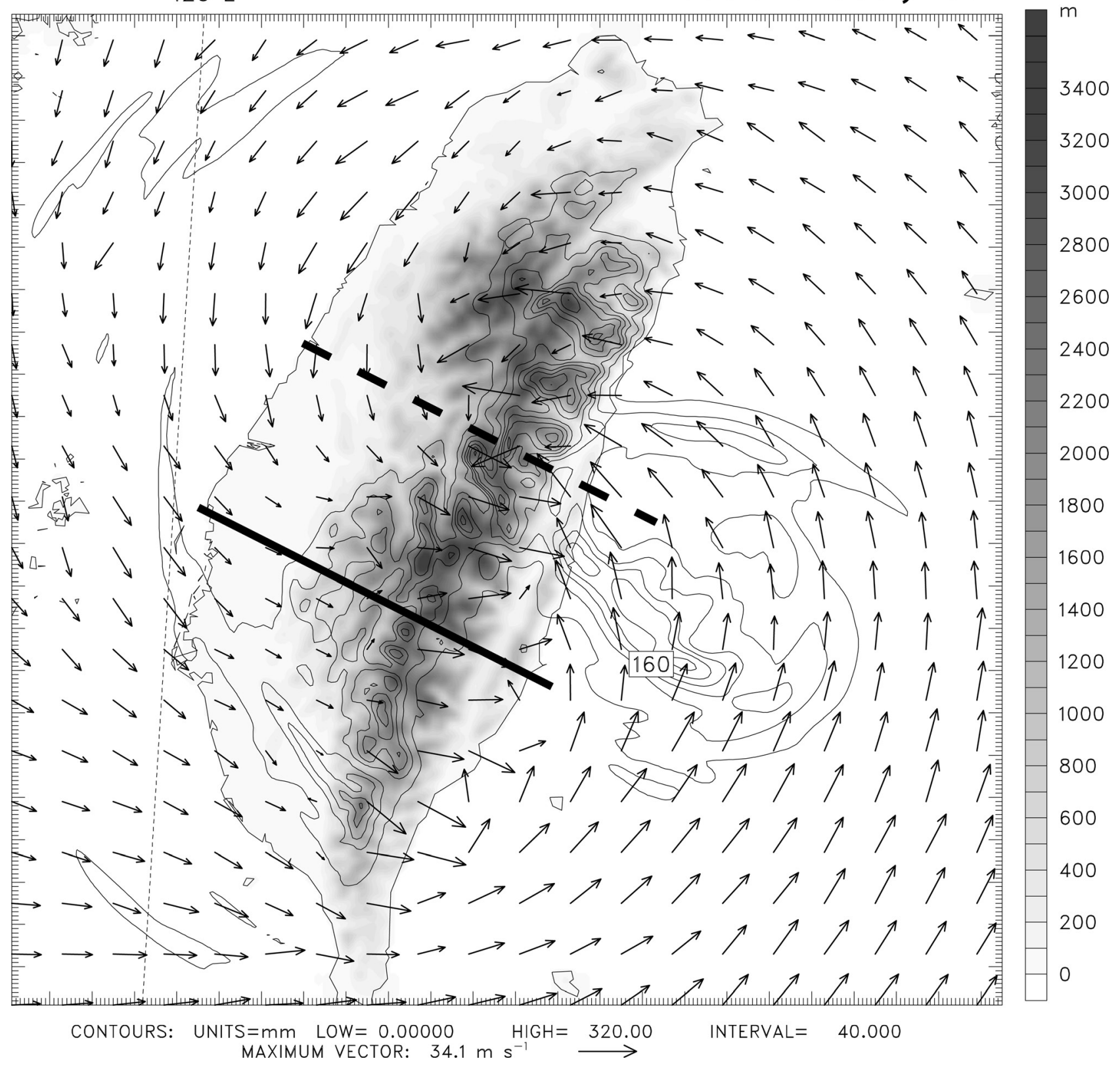

Figure 11. Model-derived near-surface winds (vectors), 3-hour accumulated precipitation (contours) and topography (gray scale) from 1600 UTC 29 July 2001. Solid and dashed bars indicate location of cross section in Figures 12a and 12b, respectively.

[41] The importance of orographic effects in southwestern Taiwan is illustrated in Figure 12a, which shows a profile of wind vectors and condensational heating at 1600 UTC on 29 July 2001 (thick line on Figure 11 indicates location of profile). The wind vectors show a westerly wind component west of the Central Range, especially below around $2 \mathrm{~km}$. As the westerly winds impinged upon the southwestern slopes of the Central Range, the air was forced upslope, causing condensation and an associated maximum in condensational heating just above the surface, with some condensational heating extending up to around $7 \mathrm{~km}$. This upslope movement thus produced heavy precipitation on the western slopes of the Central Range. On the eastern side of the Central
Range, the winds descended, generating subsidence-induced warming and drying, with no condensation and thus very little precipitation on the eastern side of the Central Range. The pattern of condensation over the southwestern Central Range thus indicates a very high degree of orographic forcing of rainfall in this area.

[42] In contrast, the condensational heating around the eyewall at 1400 UTC on 29 July 2001, during landfall in eastern Taiwan (Figure 12b) extended through a much deeper zone (up to $10 \mathrm{~km}$ ) than in southwestern Taiwan, with significant condensation occurring just above the surface on the eastern slopes of the orogen, and extending to more than $5 \mathrm{~km}$ above the surface. This pattern of condensation 

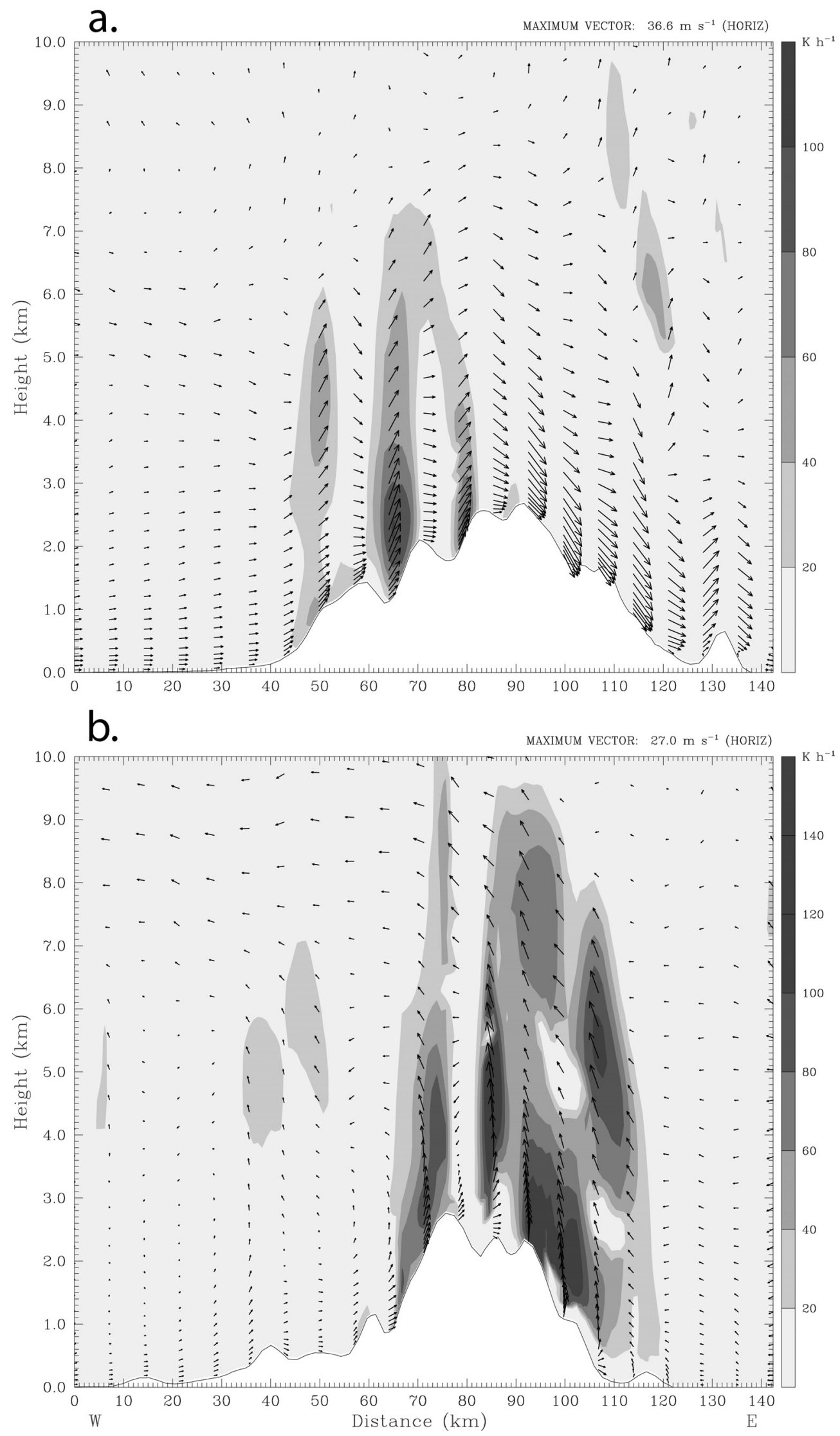

Figure 12. Cross sections of model-derived wind vectors $\left(\mathrm{m} \mathrm{s}^{-1}\right.$ in the horizontal, $\mathrm{cm} \mathrm{s}^{-1}$ in the vertical) and condensational heating $\left(\mathrm{K} \mathrm{h}^{-1}\right)$. (a) Southern Taiwan at 1600 UTC 29 July 2001; (b) Northern Taiwan at 1400 UTC 29 July 2001. Locations of cross sections are indicated in Figure 11. 

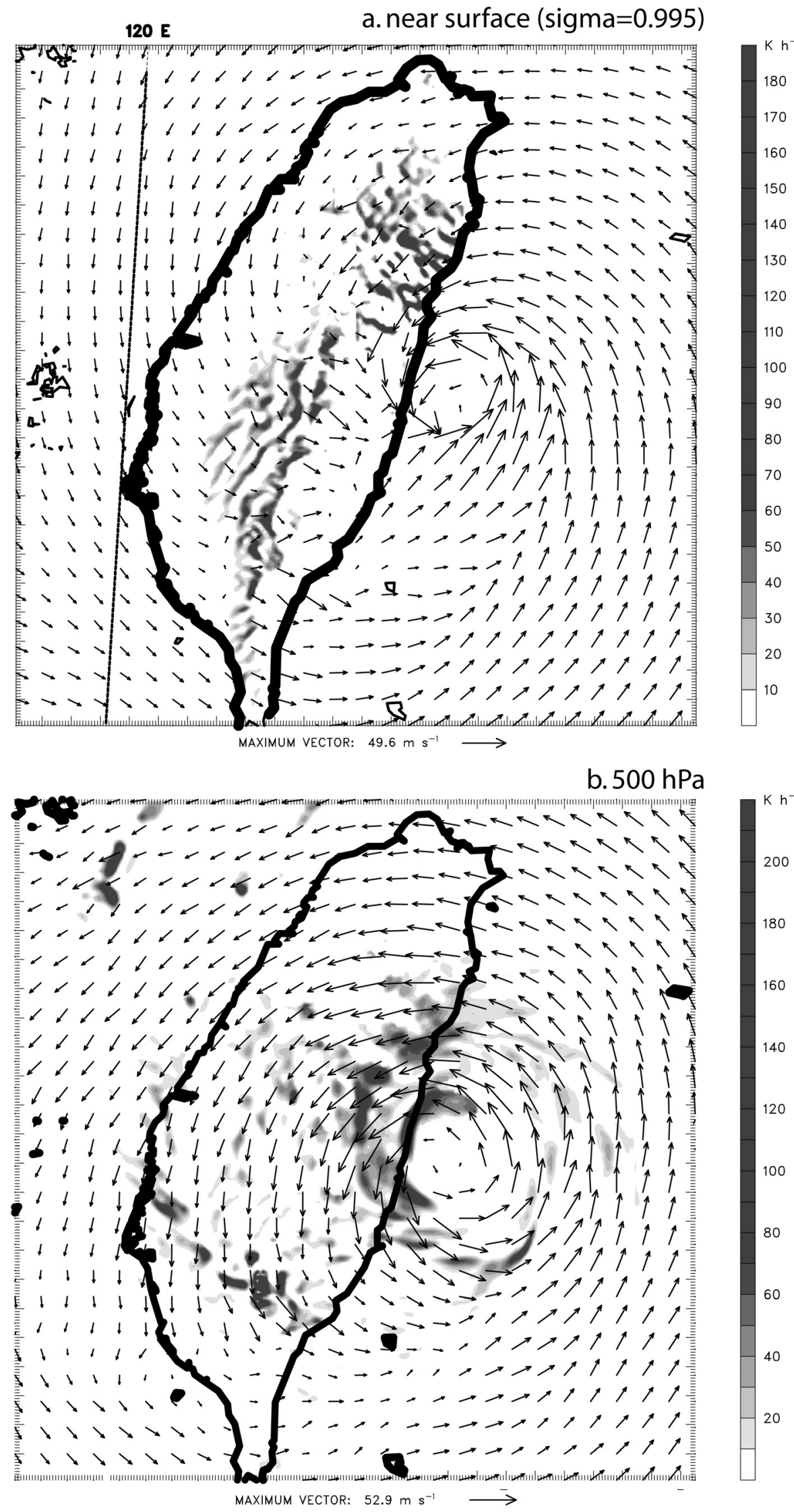

Figure 13. Model-derived wind vectors and condensational heating $\left(\mathrm{K} \mathrm{h}^{-1}\right)$ at $1300 \mathrm{UTC} 29$ July 2001. (a) Near surface $(\sigma=0.995)$ and at (b) $500 \mathrm{hPa}$. 


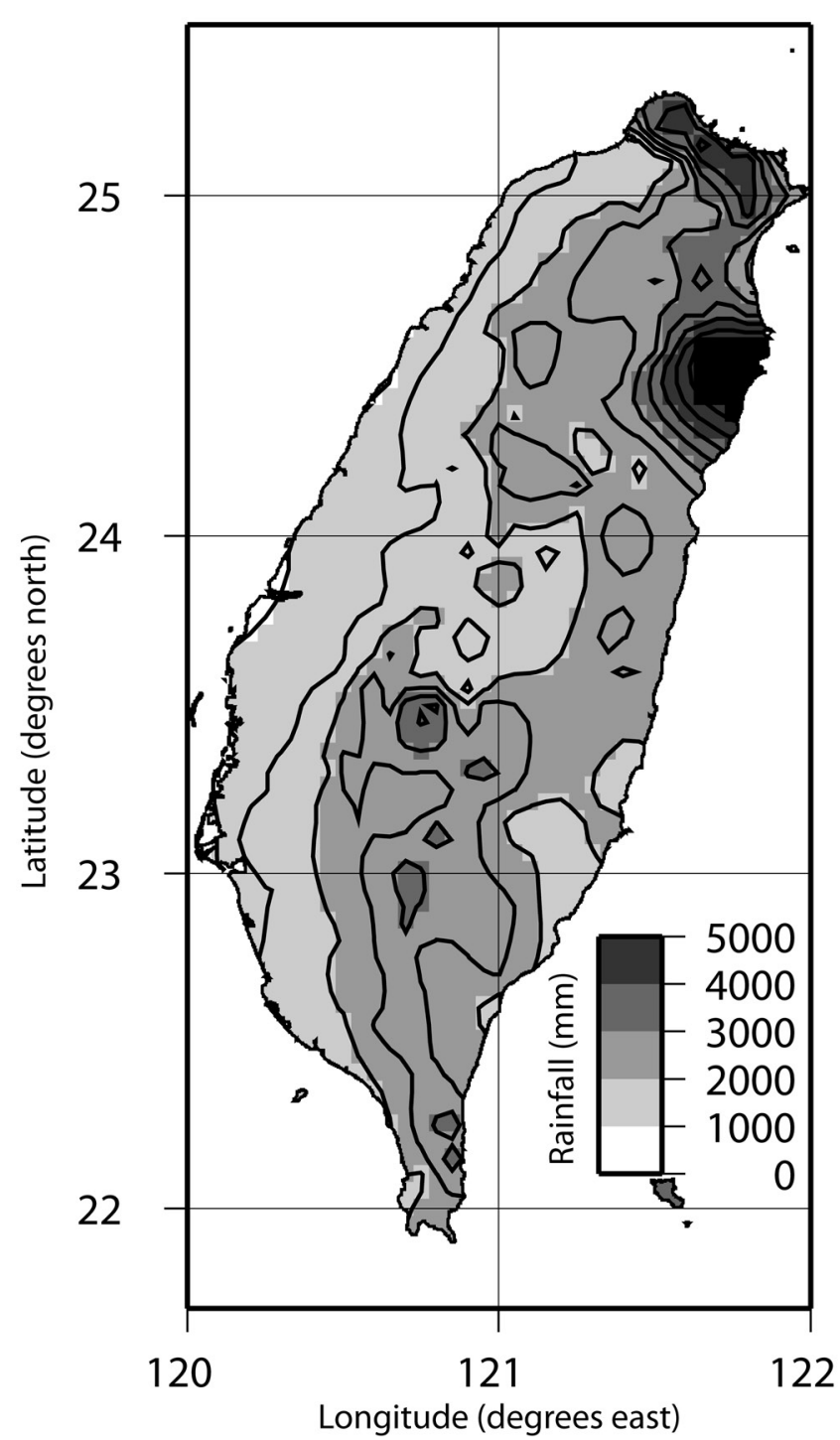

Figure 14. Mean annual rainfall, 1990-2003 (mm). Location of rain gauges used in calculation shown in Figure 2.

suggests a more complex precipitation mechanism in eastern Taiwan, with eyewall processes producing condensation well above the surface (likely to have been somewhat decoupled from topography), but with a significant component of lowlevel condensation consistent with orographic forcing.

[43] The links between atmospheric circulation and precipitation are further illustrated in Figure 13, which shows the condensational heating near the surface (Figure 13a) and above the topography at $500 \mathrm{hPa}$ (Figure 13b). Near the surface, the pattern of condensational heating closely followed the topography, illustrating the orographic effects across the Central Range. The condensational heating at $500 \mathrm{hPa}$, well above the topography, was centered around the eyewall of the tropical cyclone. The condensation at $500 \mathrm{hPa}$ is consistent with that observed in oceanic tropical cyclones unaffected by topography [Wu et al., 2002]. Thus, while the precipitation in southwestern Taiwan was directly coupled to topography, the precipitation in eastern Taiwan appears to have been partially controlled by topography, and partially controlled by internal storm dynamics decoupled from topography.

[44] We briefly summarize the two main results of the model: (1) heavy precipitation was produced in the southwestern Central Range through orographic effects related to the tropical cyclone circulation; (2) precipitation in the landfall zone of eastern Taiwan was largely forced by tropical cyclone eyewall processes that were modified by interactions with topography.

[45] Thus the high sediment discharge on the Hualien River was driven by rainfall associated with the passage of the eyewall over the east coast of Taiwan, while the sediment discharge on the Kaoping River was driven by orographically produced rainfall along the southwestern slopes of the Central Range. Finally, orographic effects coupled with the effects of the Chichi Earthquake were responsible for the high sediment discharge on the Choshui River. Thus a range of atmospheric processes, with distinctive spatial variability and varying degrees of coupling to topography, interacted with tectonic processes of limited spatial extent to produce the overall sediment discharge from Taiwan during Typhoon Toraji. We now explore the implications of this study for understanding landscape evolution in tropical mountain belts.

\section{Discussion}

[46] The mean annual rainfall field of Taiwan lacks an orographic rain shadow (Figure 14). While there is important spatial variability in the mean annual rainfall, including a general increase in precipitation with elevation, neither the east nor the west side of the Taiwan mountains is a preferred site for rainfall. This relative symmetry in the mean annual rainfall is rather different from many extratropical mountain belts, such as the Sierra Nevada of California, or the Southern Alps of New Zealand, where there are significant climatological rain shadows. The presence or absence of a rain shadow is thought to have an important influence on tectonic processes in collisional mountain belts [Willett, 1999]. Taiwan receives precipitation from a variety of different atmospheric processes, including the monsoon, wintertime cold fronts, springtime Mei-Yu fronts, and tropical cyclones. Tropical cyclones produce the highest rain rates in Taiwan and about $40 \%$ of all rainfall on the island [e.g., Chen and Chen, 2003].

[47] The results from this study show how the rainfall associated with individual tropical cyclones can be strongly influenced by orographic effects, even though there is no orographic rain shadow in the mean annual rainfall field. Tropical cyclones approach Taiwan along a wide range of trajectories (Figure 15), and each trajectory is associated with a distinctive pattern of precipitation due to the orographic effects outlined in this study. Averaging over all trajectories, however, will likely smear out some of the orographic effects of individual trajectories. Thus the mean annual precipitation in Taiwan is unrepresentative of the spatial distribution of individual extreme events.

[48] Furthermore, because of the distinctive ways that tropical cyclones interact with topography, the distribution 


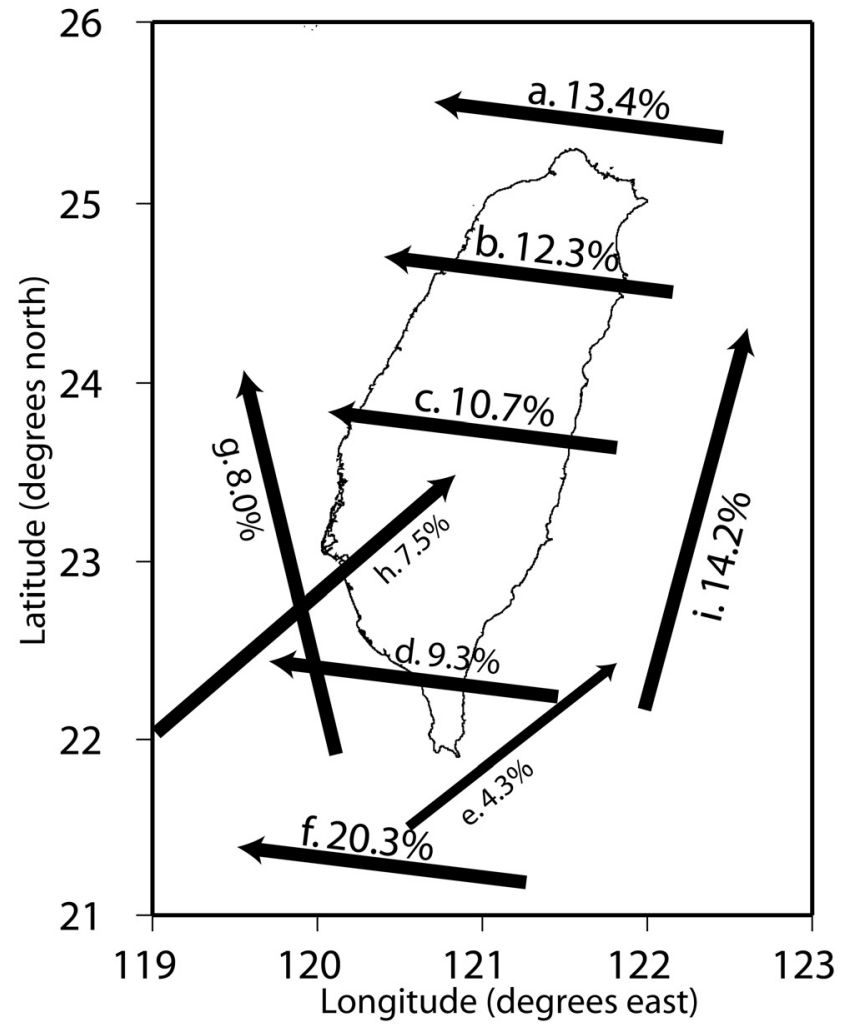

Figure 15. Typhoon track probabilities adapted from Shieh et al. [1997]. Each trajectory type has an expected occurrence expressed as a percentage of all typhoons affecting Taiwan.

of heavy rainfall and associated surface processes in Taiwan is more complex than in mid-latitude mountains. The weather systems that affect many mid-latitude mountain belts are typically controlled by prevailing westerly winds with relatively limited track variability. In contrast, tropical cyclones can approach Taiwan from a variety of directions (Figure 15). Clearly, the east coast of Taiwan receives abundant tropical cyclone rainfall due both to landfalling storms (as we have seen in Typhoon Toraji) and orographic effects of storms passing to the south (as we saw in Typhoon Utor). The southwestern Central Range also receives significant tropical cyclone rainfall due to the orographic effects of storms passing over Taiwan. This distribution of tropical cyclone rainfall is broadly consistent with the analysis of Dadson et al. [2003], who showed high decadal-scale erosion along the east coast of Taiwan and in the southwest Central Range.

[49] Models of tectonics and landscape evolution have relied on a number of idealizations of precipitation forcing. Perhaps the simplest assumption has been that of uniform precipitation across the mountain belt [Snyder et al., 2000]. Temporal variability has been modeled using Poisson models of discrete random storm events [Tucker and Bras, 2000]. Spatial variability has been included by assuming, for example, a simple dependence on relief [Dahlen and Suppe, 1988], or by assuming a rain-shadow effect in which the orogen is divided into wet windward and dry leeward slopes [Willett, 1999]. More sophisticated models have relied on parameterizing some aspects of the meteorology of orographic precipitation [Roe et al., 2003].

[50] The results presented here suggest that none of the above assumptions is likely to be valid in Taiwan, or indeed in any mountain belt dominated by tropical cyclones. Stochastic models of storm events may be adequate for understanding the temporal variability of tropical cyclone rainfall, but no current landscape evolution model captures the distinctive spatial distribution of tropical cyclone rainfall. This spatial distribution is not random, and is thus unlikely to average out in a simple sense on geological timescales. On the timescale of individual storms, the precipitation distribution and associated surficial processes depend on the physics of tropical cyclone-topography interactions as illustrated in this study; on longer timescales (decadal and beyond) they depend on the climatology of tropical cyclone tracks. Shifts in the relative probability of tropical cyclone tracks or intensity could potentially effect changes in erosion by altering the spatial distribution of heavy tropical cyclone rainfall. Changes in western Pacific tropical cyclone tracks and intensity on Holocene or longer timescales are almost entirely unknown at present, but depend on changes in sea surface temperatures as well as large-scale atmospheric processes. The proper treatment of tropical cyclones in landscape evolution models requires a better understanding of the long-term localization of precipitation and surface processes in tropical mountain belts; the present results thus point to some inadequacies in current modeling approaches.

[51] The potential for feedbacks between tectonic and climatic processes is dictated by the degree of coupling between precipitation and topography. If precipitation is a purely external forcing of landscape evolution, then there is little potential for such links; alternatively, if precipitation is directly coupled to topography, then there may be significant feedbacks [Roe et al., 2003]. Taiwan may be subjected to a range of intermediate topographic-climatic feedbacks that have not been recognized before. We have identified three components to the tropical cyclone-topography coupling in Taiwan.

[52] First, during the passage of a storm over or near a mountainous island, cyclonic winds may be forced upslope, producing localized orographically enhanced precipitation. The spatial distribution of this direct orographic effect is dependent on the particular track a tropical cyclone may take (as illustrated above in Typhoon Utor, for example). Second, the eyewall, a site of heavy rainfall regardless of topography, may be substantially deformed by topography, with some associated impact on the precipitation distribution. The precise nature of this coupling is unclear from the present study, but eyewall precipitation is almost certainly more loosely coupled to topography than the direct orographic effects described above. Third, the tracks of tropical cyclones are influenced by upstream mountainous topography [Bender et al., 1987; Yeh and Elsberry, 1993a], raising some intriguing possibilities for the long-term (i.e., Holocene and longer timescales) feedbacks between climate and tectonics in the western Pacific. The probability distribution of tropical cyclone trajectories in the west Pacific may have evolved over time in response to the changing topography of Taiwan and other mountainous islands in the western Pacific. This 
possibility, and the potential impact of tropical cyclones on tectonic processes in Taiwan, await further study.

\section{Conclusions}

[53] Typhoon Toraji struck Taiwan in July 2001 and was the first major tropical cyclone to affect the island after the 1999 Chichi earthquake. Record water and sediment discharge were observed on the Choshui, Kaoping, and Hualien Rivers. The passage of the tropical cyclone eye over the east coast of Taiwan produced intense rainfall $\left(>100 \mathrm{~mm} \mathrm{~h}^{-1}\right)$ for a short period (about 2 hours), triggering the highest sediment concentration ever recorded on the Hualien River. Orographic effects localized heavy rainfall (between 10 and $50 \mathrm{~mm} \mathrm{~h}^{-1}$ ) over the southwestern slopes of the Central Mountain Range triggering high sediment discharge on the Kaoping River and flushing landslide debris produced during the Chichi earthquake into the Choshui River. Thus a range of atmospheric processes, with distinctive spatial variability and varying degrees of coupling to topography, interacted with tectonic processes of limited spatial extent to produce the overall sediment discharge from Taiwan during Typhoon Toraji.

[54] Acknowledgments. This work was funded in part by NASA grant NNG04GA73G to AHS. Use of the MM5 was made possible by the Microscale and Mesoscale Meteorology Division of the National Center for Atmospheric Research (NCAR), which is supported by the National Science Foundation. We thank the Taiwan Central Weather Bureau for providing the rainfall data.

\section{References}

Beaumont, C., R. Jamieson, M. Nguyen, and B. Lee (2001), Himalayan tectonics explained by extrusion of a low-viscosity crustal channel coupled to focused surface denudation, Nature, 414, 738-742.

Bender, M., R. Tuleya, and Y. Kurihara (1987), A numerical study of the effect of island terrain on tropical cyclones, Mon. Weather Rev., 115, $130-155$.

Betts, A., and M. Miller (1993), The Betts-Miller scheme, in The Representation of Cumulus Convection in Numerical Models, edited by K. Emanuel and D. Raymond, p. 246, Am. Meteorol. Soc., Boston, Mass.

Brand, S., and J. Blelloch (1973), Changes in the characteristics of typhoons crossing the Philippines, J. Appl. Meteorol., 12(1), 104-109.

Brand, S., and J. Blelloch (1974), Changes in the characteristics of typhoons crossing the island of Taiwan, Mon. Weather Rev., 102, 708-713.

Burbank, D. W., A. E. Blythe, J. L. Putkonen, B. A. Pratt-Situala, E. J. Gabet, M. E. Oskin, A. P. Barros, and T. P. Ohja (2003), Decoupling of erosion and climate in the Himalaya, Nature, 426, 652-655.

Caracena, F., R. Maddox, L. Hoxit, and C. Chappell (1979), Mesoanalysis of the Big Thompson Storm, J. Atmos. Sci., 107, 1-17.

Chen, C.-S., and Y.-L. Chen (2003), The rainfall characteristics of Taiwan, Monthly Weather Rev., 131, 1323-1341.

Chiao, S., and Y.-L. Lin (2003), Numerical modeling of an orographically enhanced precipitation event associated with Tropical Storm Rachel over Taiwan, Weather Forecast., 18, 325-344.

Dadson, S. J., et al. (2003), Links between erosion, runoff variability and seismicity in the Taiwan orogen, Nature, 426, 648-651.

Dadson, S. J., et al. (2004), Earthquake-triggered increase in sediment delivery from and active mountain belt, Geology, 32(8), 733-736.

Dahlen, F., and J. Suppe (1988), Mechanics, growth, and erosion of mountain belts, Spec. Pap. Geol. Soc. Am., 218, 161-178.

Davis, C., and S. Low-Nam (2001), The NCAR-AFWA tropical cyclone bogusing scheme, technical report, Air Force Weather Agency, Offutt Air Force Base, Nebr.

Dudhia, J. (1989), Numerical study of convection observed during the winter monsoon experiment using a mesoscale two-dimensional model, J. Atmos. Sci., 46, 3077-3107.

Dudhia, J. (1993), A nonhydrostatic version of the Penn State-NCAR mesoscale model: Validation tests and simulation of an Atlantic cyclone and cold front, Mon. Weather Rev., 121, 1493-1513.

Dudhia, J. (1996), A multi-layer soil temperature model for mm5, paper presented at Sixth PSU/NCAR Mesoscale Model Users' Workshop, Natl. Cent. for Atmos. Res., Boulder, Colo.
Dunne, T. (1991), Stochastic aspects of the relations between climate, hydrology, and landscape evolution, Trans. Geomorphol. Union Jpn., $12,1-24$.

Emanuel, K. (1991), The theory of hurricanes, Annu. Rev. Fluid Mech., 23, $179-196$.

Finlayson, D., D. Montgomery, and B. Hallet (2002), Spatial coincidence of rapid inferred erosion with young metemorphic massifs in the Himalayas, Geology, 30(3), 219-222.

Galewsky, J., and A. Sobel (2005), Moist dynamics and orographic precipitation in Northern and Central California during the New Year's flood of 1997, Mon. Weather Rev., 133, 1594-1612.

Geerts, B., G. Heymsfield, L. Tian, J. Halverson, A. Guillory, and M. Mejia (2000), Hurricane Georges's landfall in the Dominican Republic: Detailed airborne Doppler radar imagery, Bull. Am. Meteorol. Soc., 81, 999-1018.

Grossman, M. (2001), Large floods and climatic change during the Holocene on the Ara River, Central Japan, Geomorphology, 39(1), 21-37.

Hellin, J., M. Haigh, and F. Marks (1999), Rainfall characteristics of Hurricane Mitch, Nature, 399, 316.

Hodges, K., C. Wobus, K. Ruhl, T. Schildgen, and K. Whipple (2004), Quaternary deformation, river steepening, and heavy precipitation at the front of the higher Himalayan ranges, Earth Planet. Sci. Lett., 220, 379-389.

Hong, S.-Y., and H.-L. Pan (1996), Nonlocal boundary layer vertical diffusion in a medium-range forecast model, Mon. Weather Rev., 124, $2322-$ 2339.

Houze, R. (1993), Cloud Dynamics, Elsevier, New York.

Lee, W., T. Shin, K. Kuo, K. Chen, and C. Wu (2001), CWB free-field strong-motion data from the 21 September Chi-Chi, Taiwan, Earthquake, Bull. Seismol. Soc. Am., 91(5), 1370-1376.

Lin, M., K. Wang, and T. Chen (2000), Characteristics of the slope failure caused by Chi-Chi earthquake, in International Workshop on Annual Commemoration of Chi-Chi Earthquake (III), edited by C. Loh and W. Lao, pp. 199-209, Natl. Cent. for Res. on Earthquake Eng., Taipei.

Lin, Y.-L., D. Ensley, S. Chian, and C.-Y. Huang (2002), Orographic influences on rainfall and track deflection associated with the passage of a tropical cyclone, Mon. Weather Rev., 130, 2929-2950.

Masek, J., N. Isacks, T. Gubbels, and E. Fielding (1994), Erosion and tectonics at the margins of continental plateaus, J. Geophys. Res., 99, $12,941-13,956$.

Molnar, P. (2003), Nature, nurture and landscape, Nature, 426, 612-614.

Montgomery, D., G. Balco, and S. Willett (2001), Climate, tectonics, and the morphology of the Andes, Geology, 29(7), 579-582.

Reiners, P. W., T. A. Ehlers, S. G. Mitchell, and D. R. Montgomery (2003), Coupled spatial variations in precipitation and long-term erosion rates across the Washington Cascades, Nature, 427, 645-647.

Roe, G. (2005), Orographic precipitation, Annu. Rev. Earth Planet. Sci., 33, $645-671$

Roe, G., D. Montgomery, and B. Hallet (2002), Effects of orographic precipitation on the concavity of steady-state river profiles, Geology, 30, 143-146, doi:10.1130/0091-7613.

Roe, G., D. Montgomery, and B. Hallet (2003), Orographic precipitation and the relief of mountain ranges, J. Geophys. Res., 108(B6), 2315, doi:10.1029/2001JB001521.

Rotunno, R., and R. Ferretti (2001), Mechanisms of intense Alpine rainfall, J. Atmos. Sci., 58, 1732-1749.

Shieh, S.-L., S.-T. Wang, M.-D. Cheng, and T.-C. Yeh (1997), User's Guide for Typhoon Forecasting in the Taiwan Area (in Chinese), vol. NSC67M-0202-01 (01), Central Weather Bur., Taipei.

Snyder, N., K. Whipple, G. Tucker, and D. Merritts (2000), Landscape response to tectonic forcing: Digital elevation model analysis of stream profiles in the Mendocino triple junction region, northern California, Geol. Soc. Am. Bull., 112, 1250-1263.

Sólyom, P., and G. Tucker (2004), Effect of limited storm duration on landscape evolution, drainage basin geometry, and hydrograph shapes, J. Geophys. Res., 109, F03012, doi:10.1029/2003JF000032.

Tao, W.-K., and J. Simpson (1993), Goddard Cumulus Ensemble Model: Part I: Model description, Terr. Atmos. Oceanic Sci., 4, 35-72.

Teng, L. (1990), Geotectonic evolution of late Cenozoic arc-continent collision in Taiwan, Tectonophysics, 183, 57-76.

Tucker, G., and R. Bras (2000), A stochastic approach to modeling the role of rainfall variability in drainage basin evolution, Water Resour. Res., 36, $1953-1964$.

Tucker, G., and R. Slingerland (1997), Drainage basin responses to climate change, Water Resour. Res., 33, 2031-2047.

Wang, Y. (2002), An explicit simulation of tropical cyclones with a triply nested movable mesh primitive equations model-TCM3: Part II: Model refinements and sensitivity to cloud microphysics parameterization, Mon. Weather Rev., 130, 3022-3036. 
Willett, S. (1999), Orogeny and orography: The effects of erosion on the structure of mountain belts, J. Geophys. Res., 104(B12), 28,957-28,981.

Wobus, C. W., K. V. Hodges, and K. X. Whipple (2003), Has focused denudation sustained active thrusting at the Himalayan topographic front?, Geology, 31(10), 861-864.

Wu, C.-C. (2001), Numerical simulation of Typhoon Gladys (1994) and its interaction with Taiwan terrain using the GFDL hurricane model, Mon. Weather Rev., 129, 1533-1549.

Wu, C.-C., and Y.-H. Kuo (1999), Typhoons affecting Taiwan: Current understanding and future challenges, Bull. Am. Meteorol. Soc., 80, 67-80.

Wu, C.-C., and Y. Kurihara (1996), A numerical study of the feedback mechanisms of hurricane-environment interaction on hurricane movement from the potential vorticity perspective, J. Atmos. Sci., 43, 2264 2282.

Wu, C.-C., T.-H. Yen, Y.-H. Kuo, and W. Wang (2002), Rainfall simulation associated with Typhoon Herb (1996) near Taiwan, Weather Forecast. 17, 1001-1015

Yeh, T.-C., and R. Elsberry (1993a), Interaction of typhoons with the Taiwan orography: Part I. Upstream track deflections, Mon. Weather Rev., 121, 3193-3212.
Yeh, T.-C., and R. Elsberry (1993b), Interaction of typhoons with the Taiwan orography: Part II. Continuous and discontinuous tracks across the island, Mon. Weather Rev., 121, 3213-3233.

S. Dadson, Centre for Ecology and Hydrology, Maclean Building, Crowmarsh Gifford, Wallingford, UK OX10 8BB. (sjdad@ceh.ac.uk)

J. Galewsky, Department of Earth and Planetary Sciences, University of New Mexico, MSC 03 2040, Albuquerque, NM 87131, USA. (galewsky@) unm.edu)

M.-J. Horng, Water Resources Agency, Ministry of Economic Affairs, Hsin-Yi Road, Taipei, Taiwan. (mjhorng@wra.gov.tw)

A. H. Sobel, Department of Applied Physics and Applied Mathematics, Columbia University, 500 West 120th Street, New York, NY 10027, USA. (ahs129@columbia.edu)

C. P. Stark, Lamont-Doherty Earth Observatory, Palisades, NY 10964, USA. (cstark@1deo.columbia.edu)

C.-C. Wu, Department of Atmospheric Sciences, National Taiwan University, Number 1, Section 4, Roosevelt Road, Taipei 10673, Taiwan. (cwu@typhoon.as.ntu.edu.tw) 